\title{
VALIDATION OF THE CSA Z107.56 STANDARD METHOD FOR THE MEASUREMENT OF NOISE EXPOSURE FROM HEADSETS
}

\author{
Gabe Nespoli, Alberto Behar \& Frank Russo \\ Department of Psychology, Ryerson University, Toronto, Ontario
}

\begin{abstract}
The CSA Standard CAN/CSA-Z107.56-06 (R2011) "Procedures for the Measurement of Occupational Noise Exposure" deals with noise exposures found in industrial settings, where in most situations, the noise source is in the far field. The Standard also provides procedures for the measurement in situations where the noise sources include sources in the near field, which is the case with headsets. The procedures involve the use of sophisticated equipment and techniques that are generally difficult to implement in the workplace. However, the Standard also provides a simple calculation method that only requires the measurement of the background noise level using a sound level meter or a dosimeter. The calculation method assumes a signal-to-noise ratio $(\mathrm{S} / \mathrm{N})$ of $15 \mathrm{dBA}$, to ensure the most comfortable listening level for speech understanding. The noise exposure level of the ear under the headset is thus obtained as the sum of the background noise level (corrected for headset attenuation and duration of the signal) plus $15 \mathrm{dBA}$ for the $\mathrm{S} / \mathrm{N}$. The objective of the present study was to assess the validity of the calculation method under different background noise conditions. Three different background noises were played at three sound levels. The noise exposure level under two headsets with different attenuations was assessed using a speech in noise paradigm. Participants were asked to adjust the signal level to comfortably understand the speech. The increase in sound level was measured for each combination of parameters using an artificial ear.
\end{abstract}

\section{RÉSUMÉ}

La norme CSA CAN/CSA-Z107.56-F06 (C2011) «Procédures relatives à la mesure de l'exposition au bruit au travail» traite de l'exposition au bruit trouvés dans les milieux industriels, où, dans la plupart des cas, la source de bruit est dans le champ lointain. La norme décrit également les procédures pour la mesure dans des situations où les sources de bruit incluent sources dans le champ proche, ce qui est le cas avec les casques. Les procédures impliquent l'utilisation de l'équipement et des techniques qui sont généralement difficiles à mettre en œuvre dans le milieu de travail sophistiqué. Cependant, la norme prévoit également un procédé de calcul simple qui ne nécessite que la mesure du niveau de bruit de fond en utilisant un appareil de mesure de niveau sonore ou d'un dosimètre. La méthode de calcul suppose un rapport signal-bruit $(\mathrm{S} / \mathrm{N})$ de $15 \mathrm{dBA}$, pour assurer le niveau sonore le plus confortable pour la compréhension de la parole. Le niveau d'exposition au bruit de l'oreille sous le casque est ainsi obtenue par la somme du niveau de bruit de fond (corrigée pour l'atténuation du casque et de la durée du signal), majoré de $15 \mathrm{dBA}$ pour le rapport $\mathrm{S} / \mathrm{N}$. L'objectif de la présente étude était d'évaluer la validité de la méthode de calcul dans différentes conditions de bruit de fond. Trois différents bruits de fond ont été joués à trois niveaux sonores. Le niveau d'exposition au bruit sous deux casques avec différentes atténuations été évaluée en utilisant un discours de paradigme de bruit. Les participants ont été invités à ajuster le niveau du signal de comprendre facilement la parole. L'augmentation du niveau de bruit a été mesuré pour chaque combinaison de paramètres à l'aide d'une oreille artificielle..

\section{INTRODUCTION}

Noise exposure is a measure of the acoustical energy entering the ear of an exposed person, providing a basic index for risk of hearing loss. In Canada, the CAN/CSA Standard Z107.56 (Canadian Standards Association, 2002) provides procedures for the measurement of noise exposure. The standard focuses on measurement of exposure from noise sources located in the far field, such as those found in industrial environments. Another section of the same standard deals with measurement of exposure from noise sources located in the near field, such as communication headsets.
The standard presents several methods for this kind of measurement. They involve the use of specialized instruments and require skills not commonly found on the shop floor. There is, however, a much simpler procedure, called the "calculation method," that only requires the measurement of the background noise at the location where the headset is used. The objective of the present study was to assess the validity of the calculation method under different background noise conditions.

Communication headsets are used in a variety of workplaces such as retail stores, call centres, airport 
control towers, and other workplaces where the operator is exposed to background noise while communicating through a headset. There are a wide variety of headsets. Some can only be used for listening purposes, while others are equipped with microphones that allow for bidirectional communication. Headsets are available in single-earpiece and double-earpiece designs. Most headsets come with a headband worn over the head. Others can be attached to a hardhat or helmet when its use is required for safety reasons.

The noise exposure level under a communication headset can be obtained using the following formula:

$$
L_{e q, T}=10 \log \left[10^{\frac{L-A T T}{10}}+\frac{t}{T} 10^{\frac{S}{10}}\right]
$$

where $\underline{L}_{e q, T}$ is the total noise exposure in $\mathrm{dBA} ; L$ is the noise level of the background noise in $\mathrm{dBA} ; A T T$ is the attenuation of the headset; $t$ is the total duration of the signal during the workday in hours; $T$ is the duration of the workday in hours; and $S$ is the equivalent sound level of the signal in dBA.

The first component of the formula relates to the background noise attenuated by the headset's cup, while the second is the contribution of the signal, corrected by the ratio of the signal duration to the total duration of the exposure.

The calculation method in the Standard assumes that the most comfortable listening level for speech understanding requires a $\mathrm{S} / \mathrm{N}$ ratio of $15 \mathrm{dBA}$. For normal hearing listeners, the most comfortable listening level leads to optimal word discrimination scores (Ullrich \& Grimm, 1976).

The parameter investigated in this study was the noise exposure increase in the headset due to the speech signal. The calculation method described in Section 7 of the CSA Standard specifies an increase of the noise level under the headset by $15 \mathrm{dBA}$. As an example, if the background noise level is $70 \mathrm{dBA}$ and the attenuation is not known, then the estimated noise level under the headset is $85 \mathrm{dBA}$. If the attenuation of the headset is known, then it is subtracted from the background noise level. Regardless of whether the attenuation of the headset is known, the final result must be corrected to take into account the total duration of the signal relative to the duration of the workday. No consideration is given to the nature and the spectral content of the background noise.

\section{TESTING METHOD}

Participants were asked to listen to speech signals (consisting of unrelated sentences) via the communication headsets under test. Simultaneously, background noise was reproduced at different levels over loudspeakers in the testing room. The participants' task was to increase the sound level of the speech signal using an attenuator until they reached the most comfortable listening level. Effort was made to ensure that participants were adjusting to the most comfortable listening level and not the threshold of hearing. Figure 1 illustrates the testing environment.

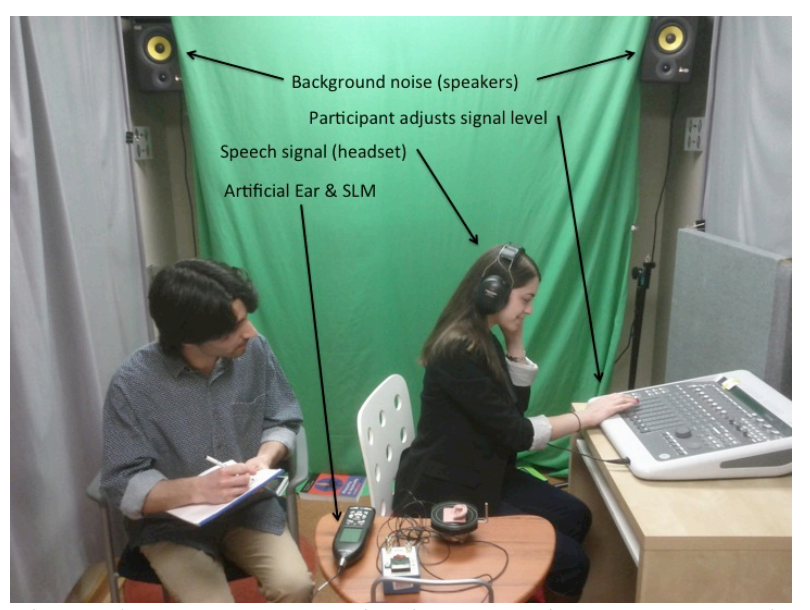

Figure 1. Background noise is played into the room via speakers, while the participant listens to the speech signal via headphones. She adjusts the signal to the most comfortable level for understanding. The experimenter then uses the Artificial Ear and Sound Level Meter to measure the noise exposure.

The CSA Standard concerns the measurement of occupational noise exposure over the duration of the workday. In our study the background noise and the speech signals had the same duration. Therefore the numerical values of noise exposure and noise level were identical.

\subsection{Test site}

Testing took place in a double-walled recording room $(3.7 \mathrm{~m} \times 2.2 \mathrm{~m} \times 2.4 \mathrm{~m})$. The room is equipped with a double glazed observation window allowing for visual communication between the experimenter and the participant. The room also supports bi-directional aural communication between the participant and experimenter. The background noise level in the room was consistently lower than $40 \mathrm{dBA}$. No special precautions were taken regarding reverberation or diffusion of the background noise sound field inside the room. 


\subsection{Equipment}

\section{Headsets and speech signal presentation}

Figure 2 is a photograph of the two headsets used in the experiment. Although both headsets entirely enclose the concha of the user, their attenuations are different. The 3M Peltor HTB79A headset was used to represent headsets with high attenuation. The Noise Reduction Rating (NRR) of the $3 \mathrm{M}$ headset as specified by the manufacturer is $26 \mathrm{~dB}$. The Koss SB-40 communication headset was chosen to represent headsets with relatively low attenuation. Koss does not provide an NRR value for this headset. The attenuator used to control the levels of the speech signal was a slider on the hardware interface (DIGI003) of the Pro Tools 8 digital audio workstation.

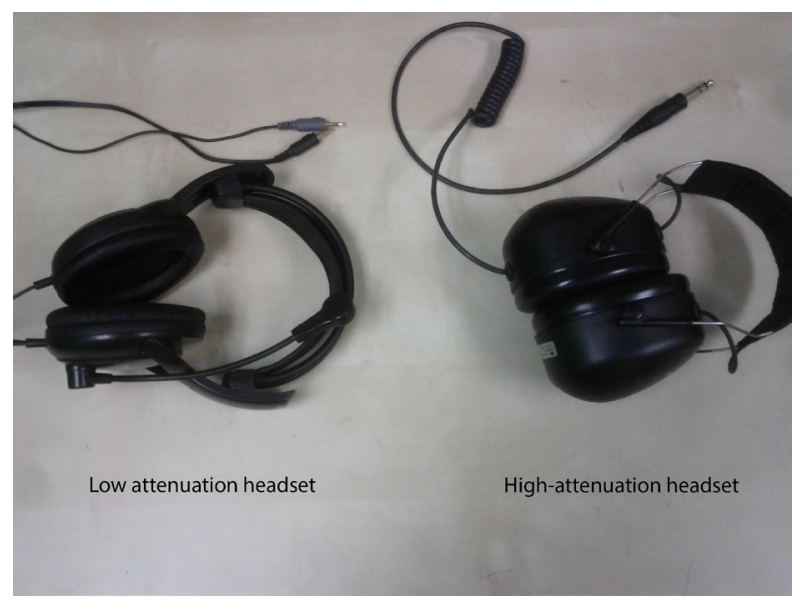

Figure 2. Photograph of the headsets used for the experiment.

\section{Background noise reproduction}

The background noise was reproduced via two KRK Rockit 5 loudspeakers located in two corners of the room. The levels of the background noises were controlled using the software interface of the Pro Tools 8 digital audio workstation.

\section{Sound level measurement}

Measurements of sound levels were performed by connecting a Type 831 Larson Davis Sound Level Meter (SLM) to a G.R.A.S. Type 43AG Ear and Cheek Simulator. Use of the simulator for these measurements is consistent with the Australian/New Zealand Standard (Standards Australia \& Standards New Zealand, 2005). Background noise measured with the simulator was found to be within +/- $1 \mathrm{dBA}$ of the equivalent measurement obtained using the SLM on its own.

\section{$\underline{\text { Audiometer }}$}

The air-conduction hearing threshold of each participant was obtained using a Grason-Stadler 61 Clinical Audiometer while seated in an IAC doublewalled audiometric booth.

\subsection{Sound signals}

\section{Background noise}

Consistent with the standard, exposure levels were determined using $\mathrm{dBA}$ as the measuring unit. Three different background noises were used for the tests as follows:

a) multi-talker babble noise to simulate acoustical conditions found in call centers, airport control towers, etc.,

b) construction noise, and

c) industrial noise.

Each noise was played at 60, 65 and $70 \mathrm{dBA}$. Diagnostic testing of speaker output revealed distortions in the signal above $70 \mathrm{dBA}$, thus we did not use sound levels above this limit. Figure 3 shows the spectra of the three noises, played at $60 \mathrm{dBA}$, as recorded in the test room using the artificial ear.

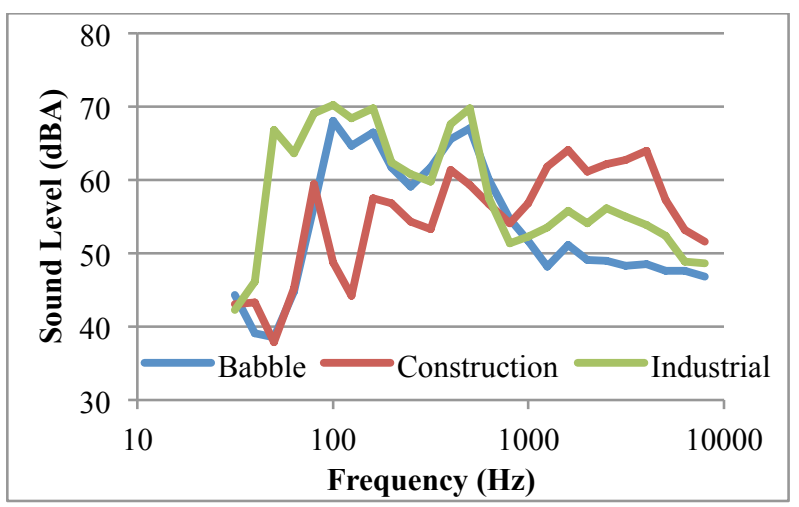

Figure 3. Spectra of the background noises used for the experiment.

\section{Speech signals}

Speech signals consisted of sentences from the revised Speech Perception In Noise test (SPIN-R; Bilger et al., 1984). The order of sentences was fixed across participants and sentences were never repeated in any two trials within the same block. 


\subsection{Participants}

Twenty-two participants were recruited from the Ryerson University community (18 females). The average age of participants was 21.6 years with a Standard Deviation of 6.5 years.

All participants had normal hearing (threshold better than $25 \mathrm{~dB} \mathrm{HL}$ ) as measured by pure tone audiometric tests at the standard test frequencies $(500,1000,2000$, 4000 and $8000 \mathrm{~Hz}$ ). Hearing thresholds were obtained after completing the study to avoid confusion between instructions for pure tones (threshold of hearing) and those for speech (most comfortable listening level). Participants were given course credit as compensation for their participation in the study.

The design of the experiment was approved by the Ryerson University Ethics Board under protocol \# 2012-251. All participants gave informed consent to take part in the study.

\section{PROCEDURE}

\subsection{Background noise calibration}

The sound level of the three background noises was adjusted to 60,65 and $70 \mathrm{dBA}$ at the start of each session.

\subsection{Testing}

Participants were given instructions on how to operate the attenuator. Before the beginning of each trial the speech signal level was set to $0 \mathrm{dBA}$ by the experimenter. Each background noise (multi-talker babble, industrial, and construction) was presented at each of three sound levels $(60,65$, and $70 \mathrm{dBA})$. Participants were instructed to adjust the level of the speech signal to the most comfortable listening level of speech understanding. Once this level was achieved, the experimenter placed the right cup of the headphone on top of the Artificial Ear and measured the $\mathrm{L}_{\mathrm{eq}}$ (speech plus background noise minus the headset attenuation) for 10 seconds. The order of trials was independently randomized for each participant.

\section{MEASUREMENT RESULTS}

The increase in noise exposure was obtained as the difference in sound level between the background noise and the combination of the background noise (reduced by the attenuation of the headset) and speech signal (adjusted by the participant), as measured by the artificial ear. To assess the reliability of these measurements, a subset of the participants completed a second block in the same session (see Appendix B).

All measurements from the first block were subjected to a $2 \times 3 \times 3$ Analysis of Variance (ANOVA) with Attenuation (high vs. low), Noise Type (babble vs. construction vs. industrial) and Noise Level (60 vs. 65 vs. 70) as within-subject factors. Significant main effects were found for Attenuation $(\mathrm{F}=982.0, \mathrm{p}<.001)$ and Noise Type $(\mathrm{F}=38.6, \mathrm{p}<.001)$, as well as a significant interaction between Attenuation and Noise Type $(\mathrm{F}=10.1, \mathrm{p}<.001)$.

The high attenuation headset yielded smaller exposure increase values (mean $=-7.6 \mathrm{dBA}$ ) than the low attenuation headset $(3.9 \mathrm{dBA})$. This is to be expected since the increased attenuation creates a quieter environment inside the headset's cups, allowing the comfortable listening level to be lower. As expected, the resulting level under the headset's cup was lower than that of the background noise itself (as indicated by the negative values). These measurement results are summarized in Figures $4 a$ and $4 b$.

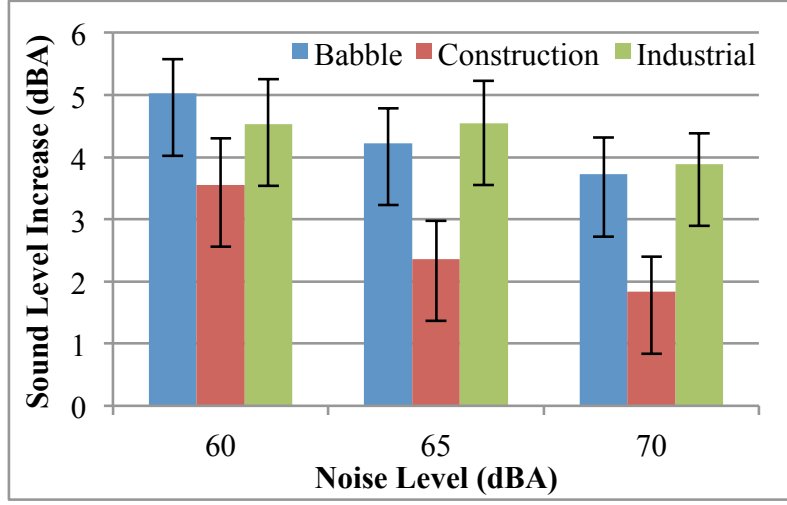

Figure 4a. Increase of sound level due to speech for the low attenuation headset. Error bars indicate standard error.

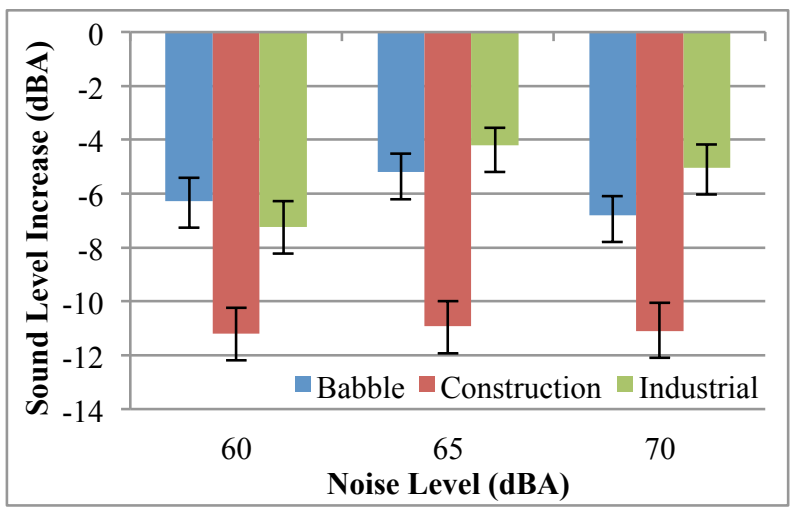

Figure 4b. Increase of sound level due to speech for the high attenuation headset. Note that all values are negative, 
indicating a decrease in sound level. Error bars indicate standard error.

Bonferroni-corrected post-hoc tests revealed that construction noise yielded significantly smaller exposure increase values (mean $=-4.1 \mathrm{dBA}$ ) compared to both babble (-0.91 dBA) and industrial noise $(-0.55)$ across both attenuation conditions $(\mathrm{p}<.001)$.

The attenuation of construction noise compared to babble and industrial noise was different for each attenuation condition, as indicated by the significant interaction of Noise Type and Attenuation. For the low attenuation headset, exposure increase values for construction noise were 1.65 and $1.71 \mathrm{dBA}$ smaller than babble and industrial noise, respectively. However, for the high attenuation headset, exposure increase values for construction noise were 4.81 and $5.46 \mathrm{dBA}$ smaller than babble and industrial noise, respectively.

\section{DISCUSSION}

The main goal of the current study was to validate the calculation method described in the CSA Standard for measuring noise exposure due to communication headsets. The calculation method stipulates that $15 \mathrm{~dB}$ should be added to an environmental sound level measurement to account for sound coming from the headset. If the attenuation of the headset is known, the measurement should first be corrected to account for this. These results confirm that the exposure increase depends on the attenuation of the headset. However it also seems that the value of $15 \mathrm{~dB}$ is too high. The increase also depends on the type of background noise, something that is not addressed in the present Standard.

When using the high attenuation headset, participants were able to achieve a comfortable listening level that was quieter than the background noise, resulting in an average exposure increase of $-7.6 \mathrm{dBA}$, which is drastically different from the $15 \mathrm{dBA}$ stipulated in the Standard. Even for the low attenuation headset, participants only needed a $3.9 \mathrm{dBA}$ increase in order to comfortably understand the speech signal.

The type of background noise also plays a role in the exposure increase due to headsets, and this is likely related to how they are differentially attenuated by the headset. Both headsets used in this study attenuated construction noise the most (see Appendix A), and correspondingly, exposure increase values were lowest for this type of noise source (see Figures $4 \mathrm{a}$ and $4 \mathrm{~b}$ ).

Interestingly, the difference in exposure increase between construction and other noises was larger for the high attenuation headset than the low one, as shown by the significant interaction. As seen in Figure 3, construction noise has a different spectral profile than babble or industrial noise, specifically one skewed towards higher frequencies. Given that higher frequencies are easier to attenuate than lower frequencies in hearing protector headsets (see Figure 3 in Berger, 2000), it makes sense that this type of noise was attenuated the most, and that the extent of attenuation was greatest in the high attenuation headset. This further strengthens the idea that the exposure increase due to headsets depends on both the attenuation of the headset and the type of background noise.

\section{CONCLUSIONS}

Results in our study cast doubt on the feasibility of having a single number to be added to the background noise level to obtain the noise level under a headset, because it is highly dependent on the type of noise in the environment Also, these results provide further validation for the advantage of high attenuation headsets, especially in high noise level environments.

\section{ACKNOWLEDGEMENTS}

We wish to acknowledge Tristan Loria for his invaluable assistance in all aspects of this project.

\section{REFERENCES}

Berger, E.H. (2000). Hearing Protection Devices. In Berger, E.H., Royster, L.H., Royster, J.D., Driscoll, D.P., \& Layne, M. (Eds.), The Noise Manual (379-454). Fairfax, VA: American Industrial Hygiene Association.

Bilger, R.C., Nuetzel, J.M., Rabinowitz, W.M., \& Rzeczkowski, C. (1984). Standardization of a Test of Speech Perception in Noise. Journal of Speech and Hearing Research, 27, 32-48.

Canadian Standards Association. (2002). Hearing Protection Devices - Performance, Selection, Car and Use. Canadian Standard CAN/CSA-Z94.2-02 (R2011). Canadian Standards Association, Toronto.

Standards Australia \& Standards New Zealand. (2005). Occupational Noise Management Part 1: Measurement and Assessment of Noise Immission and Exposure. Australian/New Zealand Standard AS/NZS 1269-1:2005. Standards Australia, Sydney, and Standards New Zealand, New York.

Ullrich, K., \& Grimm, D. (1976). Most comfortable listening level presentation versus maximum discrimination for word discrimination material. Audiology, 15, 338-347. 


\section{APPENDICES}

\section{Appendix A: Headsets' attenuation}

The attenuation of both headsets was calculated as the difference between the noise levels measured in dBA with the Artificial Ear open and covered with the headset. These results are summarized in Figures A1 and $\mathrm{A} 2$.

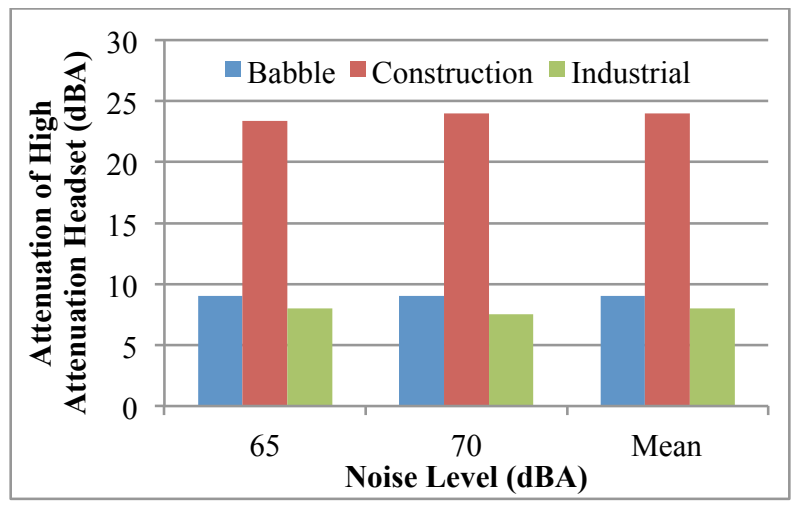

Figure A1: Attenuation of the high attenuation headset

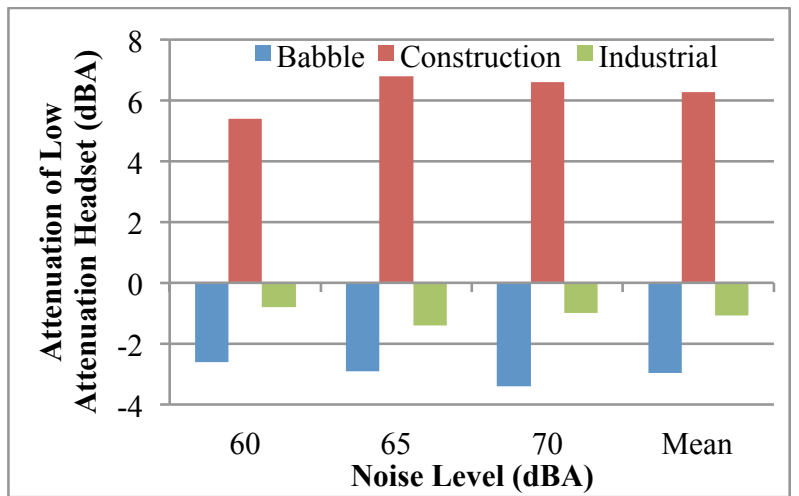

Figure A2: Attenuation of the low attenuation headset

\section{Appendix B: Reliability analysis}

Fifteen of the 22 participants completed the experiment twice in the same session (in two blocks) in order to conduct a reliability analysis. This was to ensure that participants were completing the task as instructed and not randomly setting the attenuation level. For each participant, exposure increase data for block 1 were correlated with those of block 2. The average Pearson correlation for all 15 participants was 0.86 ; all correlations were significant at least at the .001 level. As a result, data from block 2 were not included in the ANOVA that is reported in the results.

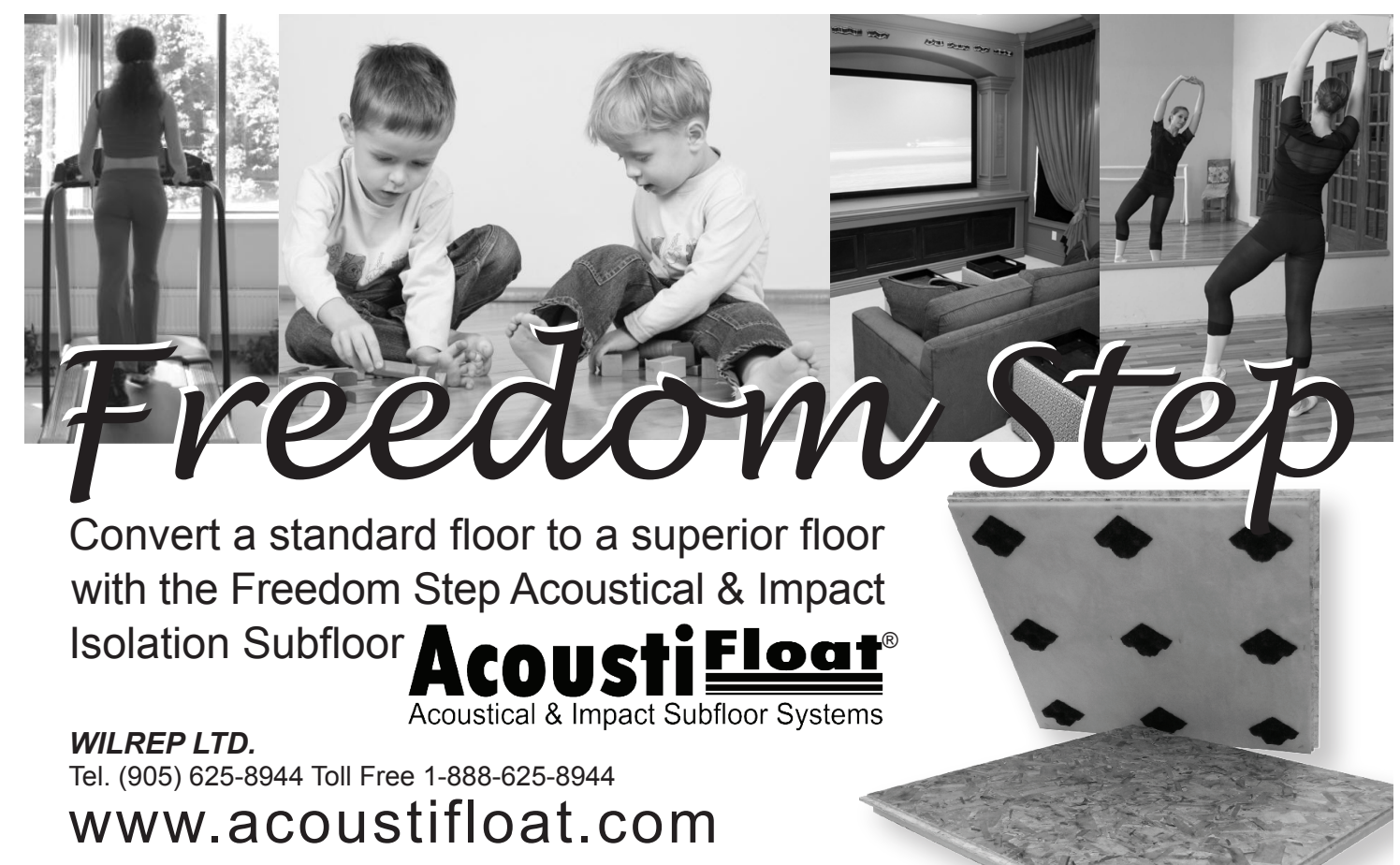

Gym Rooms Playrooms Home Theaters Dance Eloors

Acoustifloat is a registered Trademark of WILREP LTD. 